\title{
Rupture Test and Bioavailability of Oil-Soluble Vitamins
}

\section{Lipika Chablani*}

Department of Pharmaceutical Sciences, Wegmans School of Pharmacy, USA

Bioavailability of multi-vitamins as dietary supplements has always been a concern. Dissolution studies have been successfully used to predict drug release of bioactive molecules, but with vitamins there are some exceptions. United State Pharmacopoeia (USP) defines the dissolution requirements of multi-vitamin supplements based on the composition and type of dosage form. As oil-soluble vitamins do not meet the criterion of "dissolution", the performance of dosage forms containing such vitamins is evaluated by disintegration studies primarily. Dissolution studies are not applicable for such dosage forms [1].

United States Pharmacopoeia (USP) general chapter $<701>$ describes the disintegration method for evaluation of oral dosage forms, while USP general chapter $<2040>$ is regarding disintegration and dissolution of dietary supplements only. USP chapter $<2040>$ was first published in USP 30-NF 25 in 2007 [2] and since then it has been incorporated in several monographs to evaluate dosage forms used as dietary supplements. USP chapter $<2040>$ introduced "rupture test" as an alternative for evaluation of soft shell capsules. Rupture test involves use of dissolution apparatus 2 (described in USP chapter $<711>$ ), water as a medium and the paddles operating at $50 \mathrm{rpm}$. A soft shell capsule is dropped in the dissolution vessel containing $500 \mathrm{~mL}$ of water (sinkers are used if required) and paddles are rotated at $50 \mathrm{rpm}$. Capsules are observed and the time taken for the capsule shell to rupture is recorded. Capsules pass the test if six of them rupture in not more than (NMT) 15 minutes, if 1 or 2 capsules rupture more than 15 but NMT 30 minutes; test is repeated with additional 12 capsules. Out of these 18 capsules, only 2 are allowed to rupture more than 15 minutes but should rupture within 30 minutes. If all the above requirements are not met, test can be repeated with pepsin $(750,000$ units or less per $1000 \mathrm{~mL})$ added to the test medium [1]. It should be noted that the test method does not account for the ideal $\mathrm{pH}(1.5)$ required for optimal pepsin activity and a revision should be requested in this regard to chapter $<2040>$ rupture test.

There have been attempts to compare rupture test (chapter $<2040>$ ) with the disintegration test (chapter $<701>$ ). There are significant differences between these two tests which need to be studied. Table 1 highlights the differences between the two test methods.

There is limited number of soft shell capsule dietary supplements being evaluated by rupture test. However, a significant number of the products in this category are oil-soluble vitamins filled in soft shell capsules. This brings us to the fact that not enough scientific data is available for scientists to ensure that the test method is appropriate

\begin{tabular}{|l|l|l|}
\hline Difference & Chapter $<$ 701> & Chapter $<\mathbf{2 0 4 0}>$ \\
\hline Apparatus & Six cell basket rack assembly & Dissolution apparatus 2 \\
\hline Volume of test medium & $1000 \mathrm{~mL}$ & $500 \mathrm{~mL}$ \\
\hline Hydrodynamics & Up/down strokes & Rotary paddle \\
\hline Duration & NMT 45 minutes & NMT 15 minutes \\
\hline End point & No palpable firm core & Rupture of capsule shell \\
\hline
\end{tabular}

Table 1: Differences between disintegration test (USP chapter $<701>$ ) and rupture test (USP chapter <2040>). for all types of soft shell capsules containing oil-soluble vitamins/ minerals with various excipients. Lack of such information and the need of evaluating these dosage forms to establish disintegration and bioavailability correlation, is a motivation in this direction.

Few studies have been done to gain better understanding about both these test methods. A comparative study by Lobenberg et al. performed using five different soft-shell capsules (amantadine $\mathrm{HCl}$ suspension, pseudoephedrine $\mathrm{HCl}$ aqueous solution, ginseng, flaxseed oil and soya bean oil) shows that there is no advantage of using rupture test over the disintegration test. However, rupture test was quicker in end point determination than the disintegration test in most of the cases evaluated by Lobenberg et al. [3]. Thus, rupture test can provide a relatively quicker way of analysis for dietary supplements. In addition to the products Lobenberg et al. evaluated, another study by Throop et al evaluates the effect of concentration of suspended particulate matter in soft shell capsules upon aging tested by both rupture and disintegration methods. Conversely, this study indicated that both the disintegration tests are not equivalent and the results vary according to the fill content of the soft shell capsule [4]. Due to limited number of studies and scientific data, it is difficult to come to a conclusion if rupture test can be used to determine the disintegration profile and eventually bioavailability of such oil soluble vitamin based soft shell capsules or not.

Currently, USP is collecting more supporting data from different sources to address the concerns of nutraceutical/pharmaceutical companies regarding the use of chapter $<2040>$. Further scientific data using rupture test will ensure appropriate revisions for the test method and will assist in evaluation of various soft shell capsules containing oil-soluble vitamins.

\section{References}

1. Srinivasan V Srini (2001) Bioavailability of nutrients: a practical approach to in vitro demonstration of the availability of nutrients in multivitamin-mineral combination products. The Journal of Nutrition 1349S-1350S.

2. USP36-NF31 (United States Pharmacopoeia 36 - National Formulary 31). Rockville MD 2013, 975.

3. Lobenberg, Almukainzi, Mahnor S, Nadia AB Chacra, Raimar L (2011) Comparison of the rupture and disintegration tests for soft-shell capsules. Dissolution Technologies 21-25.

4. Throop c,Moolchandani V, Xu J, Penninga G, Heiter M, Hyun C (2012) Comparative evaluation of USP disintegration test vs. USP rupture test as performance test for dietary softgel supplements.

*Corresponding author: Lipika Chablani, Assistant Professor, Department of Pharmaceutical Sciences, Wegmans School of Pharmacy, St. John Fisher College, Rochester, NY, USA, Tel: +1-585-899-3714; E-mail: Ichablani@sjfc.edu

Received July 22, 2013; Accepted July 24, 2013; Published July 31, 2013

Citation: Chablani L (2013) Rupture Test and Bioavailability of Oil-Soluble Vitamins. J Bioequiv Availab 5: e37. doi:10.4172/jbb.10000e37

Copyright: @ 2013 Chablani L. This is an open-access article distributed under the terms of the Creative Commons Attribution License, which permits unrestricted use, distribution, and reproduction in any medium, provided the original author and source are credited. 